\title{
Evaluation on the Synergy Degree of Digital Finance and Regional Economic Development
}

\author{
Jiongcheng $\mathrm{Lu}^{1, *}$, Xiangding $\mathrm{Hou}^{2}$ \\ ${ }^{1}$ College of Business \& Public Management, Wenzhou-Kean University, 325060, Wenzhou, China \\ ${ }^{2}$ School of Accounting, Zhongnan University of Economics and Law, 430073, Wuhan, China \\ *Corresponding author: lujiongcheng0908@163.com
}

\begin{abstract}
To measure the level of coordinated development of digital finance and regional economy, understand the development trend of digital finance and regional economy. Based on the synergistic effect of digital finance and regional economic development, the study selects the 4 order parameters of the regional digital finance subsystems reflecting the breadth of digital finance, the depth of digital finance, and the level of digitalization and 7 order parameters of the regional economic subsystems reflecting economic structure, total economic volume, and economic benefits. Thus, the study applies the order parameter method of system synergy measure to construct the synergy evaluation model of digital finance and regional economic development and adopt the model to Peking University Hewlett-Packard Financial Index and the coordinated development of the regional economy. As a result, the synergy of digital finance and regional economy in Beijing shows an M-shaped development trend of alternating increases and decreases. The overall level of synergy is at a low level.
\end{abstract}

Keywords: Digital financial index, Regional economy, Coordination degree, Order degree

\section{INTRODUCTION}

With the trend of big Internet data, the popularization of intelligent terminal devices, and the digital transformation, digital finance continuously and profoundly affects financial markets and regional economies. Li et al. used heterogeneity analysis in 2019; according to the China Household Finance Survey (CHFS) database, the study found that the digital financial index promoted household consumption expenditure [1]. In 2021, Chen and Zhang used the multiple regression model and the Chinese National Bureau of Statistics database to find that digital finance promotes production and service and stimulates entrepreneurs to use service strategies for business reforms and upgrades[2].

In addition to the trend of digital finance, the regional economy is undergoing renewal and changes. Through investigation in 2021, Sun found that the Chinese regional economy has experienced two stages of changes in the time dimension; from different perspectives, the dimension varies accordingly [3]. Hou and Song also used the economic convergence model and Chinese provincial panel data in 2021 to show that the level of intelligence positively affects the dynamic spatial convergence of regional economic growth quality [4]. Also, the trend of digital finance is closely related to the development of the regional economy. Wu et al. used the systematic generalized matrix estimation model to perform regression in 2021. They discovered that inclusive digital finance has been promoting the quality of regional economic growth, based on the bank panel database of 31 provinces and cities from 2013 to 2019 [5]. Besides, Yuan et al. (2020) adopted the advanced panel econometric technique to analyze digitalization from 1990 to 2017. The results show that digitalization promotes technological innovation, which negatively relates to financial risk [6].

Furthermore, Geng \& He utilized the instrumental variable method and analyzed the data from the country around Belt \& Road (B\&R); they discovered that digital finance determines the sustainable employment of diverse kinds of the economy (2021)[7]. Also, Trevisan et al. (2021) conducted a systematic literature review(SLR) and explored 8 cases to discover that digitalization contributes to the circular economy [8]. Moreover, Youssef (2020) dealt with data about 310 students from 2 universities and found that digitalization deeply relates to entrepreneurial intentions [9]. In 
addition, Shen et al. (2021) investigated the World Bank and International Monetary Fund data. Using the spatial Dubin model (SDM), they discovered that digital finance contributes to economic growth [10].

The research mentioned above has contributed to the coordinated development of digital finance and the regional economy, but existing research has not paid enough attention to the coordinated development of digital finance and regional economy at the regional level. However, with the rapid rise of the digital Internet and digital finance, digital finance is an improvement of the Internet economy and good medicine for regional economic development. To accurately grasp the dynamics of digital finance and understand the impact of digital finance on the regional economy. The impact of the development will help improve the two-way development of regional economic development and digital finance. This paper takes digital finance, and regional economy as the research object constructs a coordinated measurement model of digital finance and regional economy and uses this model to measure the level of coordinated development of Beijing's digital finance and regional economy. This research provides a reference for the coordinated development of digital finance and the regional economy.

\section{THE SYNERGISTIC EFFECT OF DIGITAL FINANCE AND REGIONAL ECONOMIC DEVELOPMENT}

According to the physicist Haken's Synergetics AnIntrodution in 1995, synergy effects can be divided into external coordination and internal coordination. It combines two or more sequences, and its overall benefit is greater than the simple addition of individual sequences.[11] When the synergy effect reaches a particular critical value, the system can be changed from disorder to order, promoting the sound development of the self-organization of the composite system. Specifically, Yang and An used the entropy method and the coordinated development of the combined system with technological innovation and finance data indicators. They found that the degree of synergy between technological innovation and finance was different (2021) [12]. In this article, the digital finance index represents the breadth of digital finance, the depth of digital finance, and the level of digital finance. This paper treats digital finance and regional economy as a composite system and then studies the synergy between digital finance and regional economy. The visualization of the whole process(figure 1) is as follows:

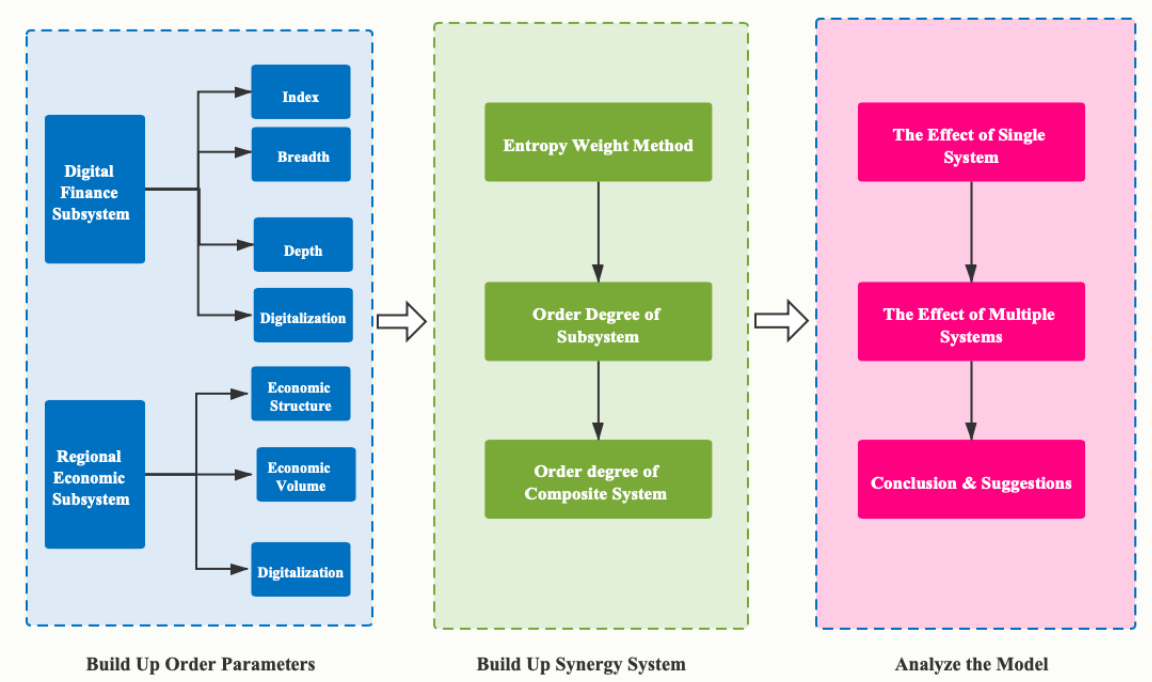

Figure 1 The Visualization of the Whole Study

\section{SYNERGY EVALUATION MODEL OF DIGITAL FINANCE AND REGIONAL ECONOMY}

\subsection{Determine the Order Parameters of Digital Finance and Regional Economic Systems}

This article starts with the order parameters of the two digital finance and regional economy subsystems, studies the synergy of digital finance and regional economic complex systems, constructs an evaluation model of synergy between digital finance and regional economy, and reveals the evolutionary trends of the system.

Based on the synergy theory, digital finance and regional economy are composite systems composed of two subsystems with different attributes and structures. Order parameter refers to the parameter variable that determines the macroscopic behaviour of the system and characterizes the degree of order of the system. It determines the final structure and degree of order of the system. The study follows the principles of systematicity and operability to determine the order parameters of 
digital finance and the regional economic subsystems. In research, the digital finance index is from the Peking University Digital Financial Inclusion Index of China (PKU-DFIIC), produced by Guo et al. (2020)[13]. The digital financial inclusion index is founded by Peking University and Ant Financial Services Group. Specifically, its sub-index holds only 4 factors. For the paper, our study regards the secondary index as the Explanatory index and the third level index as the Sub- index, explained as follows. The digital financial subsystem is divided into 4 sequence parameters, which reflects the breadth, depth, and digitalization level. The regional economic development subsystem is divided into 7 sequence parameters reflecting economic structure, economic volume, and economic benefits. The order parameters of digital finance and regional financial system are shown in Table 1.

Table 1 Order Parameters of Digital Finance and Regional Economic System

\begin{tabular}{|c|c|c|c|}
\hline Order Parameters & Explanatory index & Sub-index & Types \\
\hline \multirow{4}{*}{ Digital Financial Subsystem } & Index & Index_Aggregate & Positive \\
\hline & Breadth & Coverage_Breadth & Positive \\
\hline & Depth & Usage_depth & Positive \\
\hline & Digitalization & Digitization_level & Positive \\
\hline \multirow{7}{*}{$\begin{array}{c}\text { Regional Economic Development } \\
\text { Subsystem }\end{array}$} & \multirow{3}{*}{ Economic Structure } & $\begin{array}{c}\text { Primary Industry Output Value (ten thousand } \\
\text { yuan) }\end{array}$ & Positive \\
\hline & & $\begin{array}{c}\text { Secondary Industry Output Value(ten thousand } \\
\text { yuan) }\end{array}$ & Positive \\
\hline & & \begin{tabular}{|c|}
$\begin{array}{c}\text { Tertiary Industry Output Value(ten thousand } \\
\text { yuan) }\end{array}$
\end{tabular} & Positive \\
\hline & \multirow{2}{*}{ Economic Volume } & $\begin{array}{l}\text { Total Import and Export Trade (ten thousand } \\
\text { yuan) }\end{array}$ & Positive \\
\hline & & GDP (ten thousand yuan) & Positive \\
\hline & \multirow{2}{*}{ Economic Benefit } & $\begin{array}{c}\text { Local Fiscal Revenue } \\
\text { thousand yuan) }\end{array}$ & Positive \\
\hline & & $\begin{array}{l}\text { GDP per capita } \\
\text { (ten thousand yuan) }\end{array}$ & Positive \\
\hline
\end{tabular}

\subsection{Subsystem Order Model}

The study treats digital finance and regional economy as a composite system: $S=\left\{S_{1}, S_{2}\right\}$, from which $S_{1}$ represents digital finance subsystem $S_{2}$ represents the regional economic subsystem. Considering the $S_{j}(j \in[1,2])$ study assumes the order parameter to be $e_{j}=\left(e_{j 1}, e_{j 2}, e_{j n}\right)$, on which , $\beta_{j i} \leq e_{j i} \leq \alpha_{j i}, n \geq 1, i=1,2, n$. Besides $\alpha_{j i}$, $\beta_{j i}$ are the critical values when the system is stable.

Assuming $e_{j}=\left(e_{j 1}, e_{j 2}, e_{j n}\right)$ to be a positive indicator, its value is positively correlated with the degree of order; $e_{j}=\left(e_{j l+1}, e_{j l+2}, e_{j n}\right)$ is a negative indicator. Its value is negatively correlated with the degree of order.

Thus, based on the subsystem $S_{j}$ and order parameter component, $e_{j i}$ the degree of order $u_{j}\left(e_{j i}\right)$ is as follow:

$$
u_{j}\left(e_{j i}\right)= \begin{cases}\frac{e_{j i}-\beta_{j i}}{\alpha_{j i}-\beta_{j i}} & , i \in[1,1] \\ \frac{\alpha_{j i}-e_{j i}}{\alpha_{j i}-\beta_{j i}} & , i \in[1+1, n]\end{cases}
$$

Based on the synergy theory, the contribution of the sequence parameter to the system can be calculated by "integrating" each sequence parameter component. This paper uses the linear weighting method for integration; thus, the degree of order $u_{j}\left(e_{j}\right)$ for order parameter variable $e_{j}$ is as follow:

$$
u_{j}\left(e_{j}\right)=\sum_{j=1}^{n} \omega_{j} u_{j}\left(e_{j i}\right), \omega \geq 0, \sum_{j=1}^{n} \omega_{i}=1
$$

The formula, $\omega_{i}$ represents the weight of each order parameter。

$\omega_{i}$ is used by the entropy method to be determined. The entropy method is an objective weighting method, which reflects the potential effect of each indicator on the evaluation result under the condition of a specific value. The basic principle is as follows: 
After standardizing the data, the study calculates the proportion of the jth index of $i$-th sample in this index :

$$
u_{i j}=\frac{\alpha_{i j}}{\sum_{\alpha_{i j}}}
$$

The study calculates the entropy value of the $j$-th evaluation index $e_{j}$ :

$$
e_{j}=-k \sum_{u_{i j}} \ln \left(u_{i j}\right), k=\frac{1}{\ln (m)}
$$

The coefficient of difference of $j$-th evaluation index $g_{j}$ is as follow:

$$
g_{i}=1-e_{j}
$$

Calculate The weight of the evaluation index $\omega_{i}:$

$$
\omega_{j}=g_{j} / \sum g_{g_{j}}
$$

\subsection{Synergy Model of Composite System}

The degree of synergy between digital finance and the regional economic complex system reflects the degree of comprehensive coordination between the development of digital finance and the operation of the regional financial system, namely:

$$
\begin{aligned}
& \mathrm{U}_{(t)}=\operatorname{sig}(\cdot) \sqrt{\left|U_{1}(t)-U_{1}(t-1)\right| \cdot\left|U_{2}(t)-U_{2}(t-1)\right|} \\
& \operatorname{sig}(\cdot)=\left\{\begin{array}{l}
1, \mathrm{U}_{1}(\mathrm{t})-\mathrm{U}_{1}(\mathrm{t}-1) \geq 0, \mathrm{U}_{2}(\mathrm{t})-\mathrm{U}_{2}(\mathrm{t}-1) \geq 0 \\
-1, \text { others }
\end{array}\right.
\end{aligned}
$$

$\mathrm{U}_{1}(\mathrm{t})$ refers to the orderly contribution of the digital financial subsystem at time $t, U_{2}(t)$ is the orderly contribution degree of the regional economic subsystem at time t. For $\mathrm{U}_{(t)} \in[-1,1]$, When $\mathrm{U}_{(\mathrm{t})}$ tends to 1 , it indicates that the greater the degree of synergy between digital finance and the regional economy, the more effectively coordinated development between the digital financial system and the regional economic system, or between internal factors. When $\mathrm{U}_{\text {( } \mathrm{t})}$ becomes smaller, indicating the small coordination between the two systems, with the disorderly development between regional logistics and regional economic systems.

\section{EVALUATION OF THE SYNERGY BETWEEN DIGITAL FINANCE AND REGIONAL ECONOMIC DEVELOPMENT}

\subsection{Research Area}

Beijing is the capital and political centre of China. Beijing is also the first city to adopt the conception of open digital financial index and apply it to the financial market. Hence, the digital financial system is relatively mature, and the data resource of Beijing city is available for further research and analysis. In addition, it is an area of financial development and innovation, which affects the country's economic and financial growth. Specifically, in 2018, its regional GDP was 3,032 billion yuan. The output value of the primary industry is 11.87 billion yuan, the output value of the secondary sector is 564.77 billion yuan, and the output value of the tertiary sector is 2455.36 billion yuan. In addition, in 2018, Beijing's comprehensive technological innovation level ranked first in the country. With the gradual formation of Beijing's digital financial ecosystem and the blessing of Internet technology, the comprehensive empowerment of digital finance and the promotion of the coordinated development of digital finance and regional economy play an important role in achieving high-quality economic development.

\subsection{Data Source}

The order parameter indicators of Beijing's digital finance and regional development economic system are derived from the 2011-2018 Beijing Statistical Yearbook, Measuring China's Digital Financial Inclusion: Index

\begin{tabular}{|c|c|c|c|c|c|c|c|c|}
\hline Order Parameter & 2011 & 2012 & 2013 & 2014 & 2015 & 2016 & 2017 & 2018 \\
\hline $\begin{array}{c}\text { Primary Industry } \\
\text { Output Value }\end{array}$ & 134.5 & 148.4 & 159.8 & 159.2 & 140.4 & 129.8 & 120.4 & 118.7 \\
\hline $\begin{array}{l}\text { Secondary Industry } \\
\text { Output Value }\end{array}$ & 3753.2 & 4060.0 & 4392.8 & 4663.4 & 4660.6 & 4944.4 & 5326.8 & 5647.7 \\
\hline $\begin{array}{c}\text { Tertiary Industry } \\
\text { Output Value }\end{array}$ & 12740.2 & 14141.7 & 15777.4 & 17121.5 & 18884.7 & 20594.9 & 22567.8 & 24553.6 \\
\hline $\begin{array}{l}\text { Total Import and } \\
\text { Export Trade }\end{array}$ & 25303.9 & 25765.2 & 26691.0 & 25517.9 & 19827.7 & 18652.2 & 21923.9 & 27182.5 \\
\hline
\end{tabular}
Compilation and Spatial Characteristics, and the China Economic Quarterly, with corresponding reports from different years. The specific indicator data are shown in Table 2.

Table 2 Beijing Digital Finance and Regional Development Economic System Order Parameter Index 


\begin{tabular}{ccccccccc}
\hline GDP & 16627.9 & 18350.1 & 20330.1 & 21944.1 & 23685.7 & 25669.1 & 28014.9 & 30320.0 \\
Local fiscal revenue & 4359.1 & 4512.9 & 5566.1 & 7214.5 & 6813.8 & 9909.3 & 12212.6 & 12046.6 \\
GDP per capita & 83547.0 & 89778.0 & 97178.0 & 102869.0 & 109603.0 & 118198.0 & 128994.0 & 140211.0 \\
Index_aggregate & 79.4 & 150.7 & 215.6 & 235.4 & 276.4 & 286.4 & 329.9 & 368.5 \\
Coverage_breadth & 97.5 & 155.6 & 193.9 & 243.9 & 268.4 & 285.6 & 316.1 & 353.9 \\
Usage_depth & 72.2 & 159.4 & 247.5 & 219.9 & 234.2 & 263.7 & 357.2 & 366.8 \\
Digitization_level & 32.6 & 118.5 & 229.6 & 235.2 & 379.5 & 329.9 & 326.0 & 420.2 \\
\hline
\end{tabular}

\subsection{Determine the Index Weight}

Based on standardizing the evaluation index data for the coordinated development of Beijing's digital finance and regional economy, the study uses the formula from (3) to (6). It calculates the proportion, entropy, difference coefficient, and index weight of each index. The calculation results are shown in Table 3.

Table 3 The weights of Order Parameter Indicators of Digital Finance and Regional Economic Development System

\begin{tabular}{ccccc}
\hline Subsystem & Order Parameter & $e_{j}$ & $g_{i}$ & $\omega_{j}$ \\
\hline & $\begin{array}{c}\text { Primary Industry Output } \\
\text { Value }\end{array}$ & 0.834 & 0.166 & 0.166 \\
& $\begin{array}{c}\text { Secondary Industry Output } \\
\text { Value }\end{array}$ & 0.879 & 0.121 & 0.121 \\
Regional & Tertiary Industry Output & & & 0.141 \\
Economic & Value & 0.859 & 0.141 & 0.118 \\
Development & Total Import and Export & 0.882 & 0.118 & 0.137 \\
System & $\quad$ Trade & 0.863 & 0.137 & 0.208 \\
& $\quad$ GDP & 0.793 & 0.207 & 0.109 \\
& Local fiscal revenue & 0.109 & 0.215 \\
GDP per capita & Index_aggregate & 0.902 & 0.098 & 0.228 \\
Coverage_breadth & Usage_depth & 0.895 & 0.105 & 0.209 \\
Digital Finance & Digitization_level & 0.904 & 0.096 & 0.348 \\
\hline
\end{tabular}

\subsection{Analysis of System Order and Synergy}

Formula (2) is used to calculate the degree of order of digital finance and regional economic subsystems; on the basis, formula (7) is used to calculate the degree of synergy between digital finance and the regional economic complex system. Figure 2 shows the degree of order and synergy changes between Beijing's digital finance and regional economy.

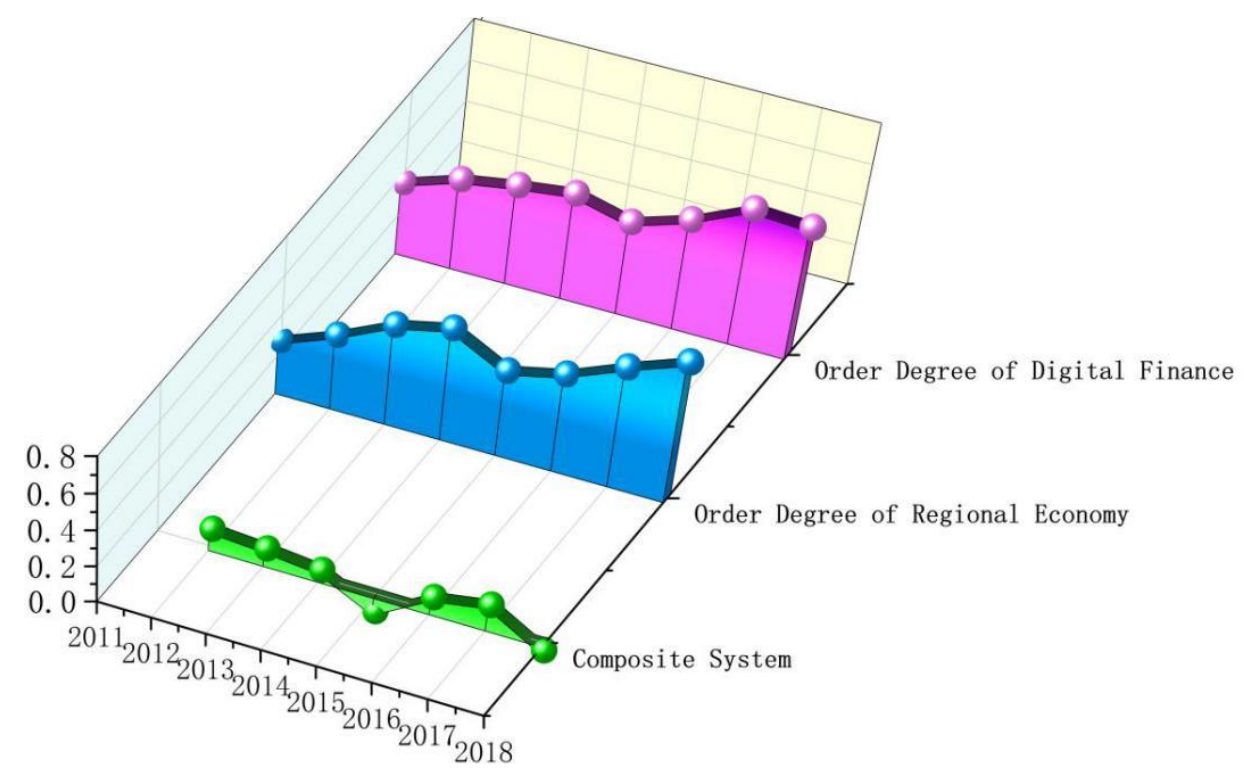

Figure 2 The Order and Coordination Changes of Beijing's Digital Finance and Regional Economy from 2011 to 
The First part is about Order analysis of subsystems: It can be seen from Figure 1 that the orderliness of Beijing's digital financial subsystem and regional economic subsystems are generally on the rising trend, and the orderliness of the regional economic subsystems is increasing at a significantly higher rate than the digital financial subsystems. The order degree of the regional economic subsystem increased from 0.2650 in 2011 to 0.7204 in 2018. In comparison, the order degree of the digital financial subsystem increased from 0.3479 in 2011 to 0.6521 in 2018 . The peak value is 0.7204 . By comparing the degree of order of the two subsystems of digital finance and regional economy, it can be seen that from 2011 to 2012, the degree of order of digital finance is significantly higher than that of the regional economic subsystem; it indicates that digital finance is ahead of the regional economy and supports the regional economy. From 2012 to 2014, the order of the regional economic subsystem was significantly higher than that of the digital financial subsystem, indicating that the development of the regional economy was increasing rapidly. From 2014 to 2017, digital finance was significantly higher than the regional economic subsystem, and the orderliness of the digital financial subsystem has quickly grown. During the period between 2017 and 2018, the effectiveness of the regional economic subsystem is higher than the digital financial subsystem. The growth rate is also higher than that of the digital financial subsystem.

The second part is about the analysis of the degree of the synergy of the hybrid system. It can be seen from Figure 2 that the degree of coordination between Beijing's digital finance and regional economic development shows an M-shaped development trend of alternating increases and decreases, and the overall level of coordination is at a low level. The general change trend of the synergy degree of the composite system can be divided into four stages:

(1) From 2011 to 2014, both digital finance and regional economy rose rapidly, while the rate of regional economic growth was slightly higher than that of the digital financial system, and its development began to lag behind digital finance. Then the regional economy was ahead of the growth rate of digital finance. Meanwhile, the coordination degree of the composite system is positive, which means that the two subsystems are always in a cooperative state.

(2) In 2015 , the orderliness of digital finance and the orderliness of the regional economy experienced a severe decline trend. At this time, the synergy of the composite system was negative, indicating that the two subsystems were incompatible.

(3) From 2016 to 2017, digital finance and the regional economy show a rapid growth trend and a slower growth trend. The orderliness of digital finance has always been higher than that of the regional economic system, indicating that digital finance is ahead of the regional economy; This stage has been at a positive value, indicating that the two subsystems have been a cooperative state.

(4) In 2018, the orderliness of digital finance showed a severe decline, but the orderliness of the regional economy grew rapidly, and the regional economic system was ahead of the digital financial system; the synergy of the composite system was negative, and the two subsystems were out of balance, unable to produce synergistic effects.

\section{CONCLUSION}

(1) From the perspective of system analysis, the study selects the sequence parameters of 4 order parameters about regional digital finance subsystems that reflect the breadth of digital finance, the depth of digital finance, and the level of digital finance digitalization. The study also selects 7 order parameters about regional economies that reflect the economic structure, aggregates, and benefits. The order parameter of the subsystem evaluates the level of coordinated development of digital finance and the regional economy.

(2) The study determines the order parameters of digital finance and regional economic systems according to the principle of constructing order parameters of digital finance and regional financial systems, establishes a synergy evaluation model between digital finance and regional economy, and determines the method of measuring the synergy level of digital finance and regional economy.

(3) Taking Beijing as an example, the model is applied to evaluate synergy between digital finance and regional economic development. The results show that the coordination degree of the composite system of Beijing's regional logistics and regional economy presents an M-type development trend of alternating increases and decreases, and it is generally in a low-level coordination stage.

\section{REFERENCES}

[1] Li, J., Wu, Y., \& Xiao, J. J. (2020). The impact of digital finance on household consumption: Evidence from China. Economic Modelling, 86, 317-326.

[2] Chen, S., \& Zhang, H. (2021). Does digital finance promote manufacturing service: Micro evidence from China. International Review of Economics \& Finance.

[3]Sun, J.(2021). The Subject Development and Innovation of Chinese Regional Economics. Regional Economic Review, 04,5-9. Retrieved from doi:10.14017/j.cnki.2095-5766.2021.0062 
[4]Hou, S. \& Song, L.(2021). The Impact of Intelligentization on the Quality of Regional Economic Growth and Its Internal Mechanism: Based on 2012 - 2018 Provincial Panel Data in China. Journal of Guangdong University of Finance \& Economics, 4,4-16.

[5]Wu, T., Liu, Y. \& Hu, Y.(2021). An Empirical Study on the Influence of Inclusive Finance on Regional Economic Development. New Finance. 7,15-20. Retrieved from DOI:CNKI:SUN: XJRO.0.202107-003.

[6] Yuan, S., Musibau, H. O., Genç, S. Y., Shaheen, R., Ameen, A., \& Tan, Z. (2021). Digitalization of economy is the key factor behind fourth industrial revolution: How G7 countries are overcoming with the financing issues. Technological Forecasting and Social Change, 165, 120533.

[7] Geng, Z., \& He, G. (2021). Digital financial inclusion and sustainable employment: Evidence from countries along the belt and road. Borsa Istanbul Review.

[8] Trevisan, A. H., Zacharias, I. S., Castro, C. G., \& Mascarenhas, J. (2021). Circular economy actions in business ecosystems driven by digital technologies. Procedia CIRP, 100, 325-330.

[9] Youssef, A. B., Boubaker, S., Dedaj, B., \& Carabregu-Vokshi, M. (2021). Digitalization of the economy and entrepreneurship intention. Technological Forecasting and Social Change, 164, 120043.

[10] Shen, Y., Hu, W., \& Hueng, C. J. (2021). Digital Financial Inclusion and Economic Growth: A Cross-country Study. Procedia Computer Science, 187, 218-223.

[11]Haken, H., Wunderlin, A., \& Yigitbasi, S. (1995). An introduction to synergetics. Open Systems \& Information Dynamics, 3(1), 97-130.

[12]Yang, N. \& An, Z.(2021). A Study on the Synergistic Effect of Sci-tech Innovation and Sci-tech Finance: An empirical Analysis Based on Shaanxi Province Date. Journal of Xi'an University of Finance and Economics,3,43-52. Retrieved from doi:10.19331/j.cnki.jxufe.2021.03.004.

[13] Guo, F., Wang, J., Wang, F., Kong, T., Zhang, X., Cheng, Z., "Measuring China's Digital Financial Inclusion: Index Compilation and Spatial Characteristics", China Economic Quarterly, 2020, 19(4). 